\title{
Floração e chuva de sementes em mata secundária em São Paulo, SP
}

\author{
ELIZABETH DE F. PENHALBER ${ }^{1}$ e WALDIR MANTO VANI ${ }^{1}$
}

(recebido em 02/01/96; aceito em 02/05/97)

\begin{abstract}
Flowering and seed rain in a secondary forest in São Paulo, southeastern Brazil). Flowering and seed rain in a secondary forest in São Paulo, southeastern Brazil, were studied through the collection of reproductive material obtained from seed traps of $0.5 \times 0.5 \mathrm{~m}$. Collections were made on a monthly basis between January and December, 1993. Ninety species belonging to 37 families were identified in the collected reproductive material. Seasonal flowering and fruiting patterns were observed in the forest. The majority of the species flowered from September; peaks in the flower and fruit abundance were observed in November. The flowering pattern was the same observed in other forests of the region, but the fruiting pattern was more seasonal. From the seed rain, it could be deduced that the anemochorous species dispersed their seeds mainly in November, at the onset of the rainy season and not in the dry season as was expected. The majority of zoochorous species dispersed their seeds during the middle of the rainy season, with a peak in January, when the conditions for fruit ripening, seed dispersal and seedling establishment were optimal. The largest quantity of seeds was produced by the lianas while the group of trees was the richnest in species.
\end{abstract}

RESUMO - (Floração e chuva de sementes em mata secundária em São Paulo, SP). O florescimento e a chuva de sementes foram estudados em trecho de mata secundária em São Paulo, SP, através da coleta de material reprodutivo depositado em peneiras de 0,5 x 0,5 m, recolhido mensalmente entre janeiro e dezembro de 1993. Foram identificadas 90 espécies pertencentes a 37 famílias. Observaram-se padrões sazonais de floração e de frutificação, sendo que a maioria das espécies floresceu a partir de setembro, com picos de floração e de frutificação em novembro. O padrão de floração encontrado foi o mesmo verificado em outras florestas da região, sendo o de frutificação mais sazonal. Na chuva de sementes, as espécies anemocóricas dispersaram propágulos predominantemente em novembro, no início das chuvas e não durante a estação seca, como esperado. A maioria das espécies zoocóricas liberou propágulos durante o meio da estação chuvosa, com pico em janeiro, na época de melhores condições de amadurecimento do fruto, dispersão de sementes e estabelecimento de plântulas. As lianas produziram a maior quantidade de propágulos, enquanto das arbóreas obteve-se o maior número de espécies.

Key words - Flowering, seed rain, secondary forest, São Paulo, Brazil

\section{Introdução}

O estudo da fenologia é de grande importância para a compreensão da dinâmica dos ecossistemas florestais (Fournier 1976), fornecendo informações básicas para o estudo de populações e de aspectos interativos nas comunidades.

Os trópicos apresentam, em geral, ricos padrões sazonais de produção de folhas e de reprodução de plantas (Bullock \& Solis-Magallanes 1990), sendo que as épocas de floração e de frutificação dependem principalmente de estímulos ambientais externos. Fatores físicos, tais como fotoperíodo, temperatura e umidade foram identificados como estímulos ao início da floração (Rathcke \& Lacey 1985), sendo que para muitas espécies, as primeiras chuvas após a estação seca parecem desencadear a floração sincrônica dos vários indivíduos (Opler et al. 1976). A disponibilidade de água para as plantas, porém, não depende só da chuva, mas também das

1. Departamento de Ecologia Geral, Instituto de Biociências USP, Caixa Postal 11461, 05422-970 São Paulo, SP, Brasil. E-mail:wmantnova@ib.usp.br condições do solo e da hidrologia local (Bullock \& Solis-Magallanes 1990).

Em florestas tropicais as árvores produzem flores de curta longevidade, que duram, para a maioria delas, apenas um dia, coincidindo antese e queda. A baixa longevidade encontrada nos trópicos pode ser, ainda, uma estratégia para minimizar a predação e diminuir o tempo de maturação do fruto (Primack 1985).

O período de dispersão dos propágulos depende diretamente da fenologia das espécies e, quase sempre, está relacionado a melhores condições para liberação de sementes e para o estabelecimento de plântulas (Rathcke \& Lacey 1985). A dispersão pode ser considerada uma estratégia reprodutiva, pois permite que os propágulos evitem as altas taxas de mortalidade próximo à planta matriz e possam colonizar ambientes mais afastados, propícios à germinação (Howe \& Smallwood 1982).

A variação anual na produção de frutos e de sementes influencia o recrutamento das populações e representa, ainda, um importante componente no potencial de regeneração de uma floresta. Aspectos do banco e da chuva de sementes permitem a avaliação do papel de populações arbóreas que 
podem se estabelecer após perturbações (Putz \& Appanah 1987).

O conhecimento fenológico é importante para qualquer plano de manejo de florestas (Fournier 1976), no entanto, há poucos estudos de fenologia e de chuva de sementes em florestas pluviais ou estacionais na região sudeste do país. Os poucos trabalhos realizados indicam que a floração é um fenômeno sazonal, que ocorre principalmente no final da estação seca e início da estação chuvosa (Jackson 1978, Matthes et al. 1988, Morellato et al. 1989, Rossi 1994, Baider 1994). Segundo Morellato (1992), a floração na transição da estação seca para a úmida parece ser um padrão comum às florestas semidecíduas do sudeste do Brasil. Os frutos são liberados durante todo o ano, sendo os frutos secos liberados predominantemente na época seca e os carnosos no início da estação chuvosa (Morellato et al. 1989, Rossi 1994). Estes autores relacionam os padrões encontrados com melhores condições de polinização, dispersão e estabelecimento de plântulas. Excetuando-se os trabalhos de Jackson (1978) e de Baider (1994), todos os demais analisaram padrões fenológicos da comunidade a partir de dados obtidos de populações, geralmente de árvores, que tiveram indivíduos marcados e acompanhados em intervalos de tempo.

Entre vários métodos para o estudo de eventos fenológicos, diversos autores utilizaram peneiras coletoras para estudos da chuva de sementes (Jackson 1981, Augspurger \& Franson 1988, Schupp 1990, Lugo \& Frangi 1993, Walker \& Neris 1993, Chapman et al. 1994, Greene \& Johnson 1994, Herrera et al. 1994, White 1994) e de aspectos da fenologia (Jackson 1978, Wright \& van Schaik 1994) em comunidades vegetais nos trópicos. Entre as vantagens apresentadas para este método está a facilidade de distinção entre botões e flores e entre frutos imaturos e maduros, dificilmente distingüíveis pela simples observação em algumas espécies (Bullock \& Sollis-Magalhanes 1990).

O objetivo deste trabalho foi determinar os padrões de floração e de frutificação em floresta secundária sob clima de duas estações. Esperou-se encontrar padrão semelhante ao descrito por outros autores para florestas no sudeste (Jackson 1978, Matthes et al. 1988, Morellato et al. 1989, Rossi 1994, Baider 1994), uma vez que as condições climáticas locais são semelhantes.
Pretendeu-se, também, determinar a composição e o padrão temporal da chuva de sementes, verificando as variações que ocorrem entre as formas de crescimento e as síndromes de dispersão. Esperouse que a época de amadurecimento e liberação de propágulos estivesse relacionada a melhores condições de dispersão (Morellato et al. 1989, Rossi 1994) e de germinação de sementes, sendo a época chuvosa a mais favorável para o estabelecimento (Garwood 1983, Rathcke \& Lacey 1985, Morellato et al. 1989).

\section{Material e métodos}

Local de estudo - Este estudo foi realizado no Parque Estadual das Fontes do Ipiranga (Parque do Estado), localizado no interior da região metropolitana de São Paulo (SP), entre as coordenadas $23^{\circ} 38^{\prime}-23^{\circ} 40^{\prime} \mathrm{S}$ e $46^{\circ} 36^{\prime}-46^{\circ} 38^{\prime} \mathrm{W}$. A área total do parque é de 549,31 ha, ocupando a mata cerca de 345 ha, delimitados em uma Reserva Biológica. O clima da região é do tipo Cwa (Köeppen 1948). As médias anuais de temperatura situam-se entre $17^{\circ} \mathrm{C} \mathrm{e}$ $19,5^{\circ} \mathrm{C}$, sendo fevereiro o mês mais quente e julho, o mais frio (Gomes 1992). O regime pluviométrico é tipicamente tropical, com duas estações definidas, sendo o inverno relativamente seco e o verão chuvoso, com as chuvas iniciando-se em setembro e concentrando-se entre outubro e março. O ano de estudo (1993), com temperatura média anual de $19,5^{\circ} \mathrm{C}$ e precipitação total de 1304,1 mm (dados: Estação Meteorológica do Instituto Astronômico e Geofísico - IAG), pode ser considerado atípico, tendo sido mais quente e seco do que a média de anos anteriores. A baixa precipitação observada no mês de novembro gerou déficit hídrico numa época normalmente caracterizada pela presença de muitas chuvas. A vegetação do parque é secundária, situando-se em região de transição dos domínios das florestas pluviais na encosta Atlântica e da mata estacional do interior do estado. Apresenta variações na composição florística de acordo com o trecho analisado (Struffaldide Vuono 1985, Gomes 1992, Nastri et al. 1992), e não há formação de dossel contínuo. No trecho estudado, as maiores árvores possuem de 8 a $12 \mathrm{~m}$. São abundantes as árvores mortas, assim como a presença de clareiras. $\mathrm{O}$ sub-bosque é dominado por lianas e pelo bambusóide Olyra micrantha (Gramineae), que cobre grandes porções do solo. Entre as espécies mais abundantes no componente arbóreo destacam-se: Ouratea semiserrata (Ochnaceae), Plinia glomerata e Myrcia pubipetala (Myrtaceae), Maytenus alaternoides (Celastraceae), Coccoloba arborescens (Polygonaceae), Amaioua guianensis (Rubiaceae), Guatteria australis (Annonaceae), Alchornea sidifolia e Pera glabrata (Euphorbiaceae) e Syagrus romanzoffiana (Palmae). A morte de indivíduos adultos do dossel, com a alteração da estrututura de diversas populações deste estrato, levou a que populações do sub-bosque apresentassem uma participação relativamente maior na estrutura fitossociológica (Gomes 1992).

Metodologia - No interior de cada uma das 40 parcelas de 10 por $25 \mathrm{~m}$ delimitadas para levantamento fitossociológico realizado anteriormente (Gomes 1992), foi instalada uma peneira quadrada de sarrafo, de $0,25 \mathrm{~m}^{2}$, com tela de malha de 2 por $2 \mathrm{~mm}$, a $15 \mathrm{~cm}$ de altura do solo. Entre janeiro e dezembro de 1993, o material depositado nestas peneiras foi recolhido mensalmente, seco e separado em botões, flores, frutos e sementes, que foram 
identificados segundo o sistema de Engler \& Prantl (Joly 1985), e quantificados separadamente para cada espécie. Foram consideradas em floração e em frutificação as espécies que tiveram amostrada ao menos uma estrutura reprodutiva nas peneiras coletoras. As amostras encontram-se na coleção do Departamento de Ecologia Geral (USP). No caso de espécies com flores de sexos separados, a quantificação foi feita para cada um deles distintarnente. $\mathrm{O}$ material não identificado foi quantificado separadamente em morfos. O termo propágulo foi utilizado em seu sentido mais amplo, referindo-se a todas as unidades de dispersão que não apresentaram sinais de danos ou anormalidades. Outros autores comumente empregam o termo "seed" neste sentido (Grime et al. 1981, Silvertown 1981, Roberts 1986). Foram calculadas as densidades (unidades $/ \mathrm{m}^{2}$ ) mensais de botões, flores, frutos imaturos e propágulos para as espécies amostradas (MuellerDombois \& Ellenberg 1974). As espécies foram separadas quanto à forma de crescimento em arbóreas, arbustivas, herbáceas e lianas (Ramirez 1993), e quanto à síndrome de dispersão, segundo Pijl (1982), em anemocóricas, zoocóricas e autocóricas. Com exceção das lianas, cuja composição em espécies muda pouco durante a sucessão (Putz 1984), as restantes foram identificadas quanto ao estádio sucessional a que pertencem, conforme Budowsky (1965) e Tabarelli et al. (1993), em: pioneiras, secundárias, clímaces e características de sub-bosque

\section{Resultados}

No material proveniente das peneiras coletoras foram identificadas 90 espécies pertencentes a 37 famílias (tabela 1). As famílias mais ricas foram, em ordem decrescente, Rubiaceae ( 9 espécies), Compositae, Euphorbiaceae (6 espécies), Leguminosae, Gramineae e Myrtaceae (5 espécies). Esta tabela traz, ainda, as épocas de floração e/ou de frutificação para as espécies amostradas. A época de floração inclui as fases de botão e flor e a de frutificação foi dividida em frutos em desenvolvimento e propágulos maduros.

As espécies mais abundantes e freqüentes no estudo fenológico foram: Mikania cordifolia, M. laevigata, M. micrantha, Piptocarpha oblonga, Alchornea sidifolia, Olyra micrantha, Miconia cabucu, Myrcia rostrata, Ouratea semiserrata e Trigonia paniculata.

Nem todas as espécies identificadas apresentaram as duas fenofases observadas. Muitas apresentaram somente flores, entre elas: Cordia sellowiana, Croton lundianus, Andira anthelmia e Miconia pyrifolia. Foram amostradas apenas em frutos, Cariniana estrellensis, C. legalis, Gochnatia paniculata, Leandra purpurascens, Pennisetum purpureum, Psidium cattleyanum, Rapanea umbellata, Rudgea gardnerioides e Valeriana scandens. Algumas destas dispersam propágulos pelo vento, o que pode indicar proveniência de locais mais afastados das peneiras. As flores, em geral, caem próximas à planta, enquanto os propágulos podem ser dispersos por distâncias mais longas, através de seus vetores de dispersão.

Para a maioria das espécies, as épocas de floração e de frutificação são bem próximas, demonstrando o rápido desenvolvimento do fruto.

Floração - Apenas 31 espécies, ou 34\% do total, foram amostradas e identificadas na fase de botão. A figura 1A mostra a distribuição do número de botões ao longo dos meses, totalizando 950,8 botões $/ \mathrm{m}^{2}$. Nota-se um pequeno aumento em abril, determinado pela grande quantidade de botões de Davilla rugosa e, a seguir, um aumento em julho, ocasionado por Piptocarpha oblonga. A partir de setembro iniciou um pico de produção, acompanhado pelo aumento do número de espécies em início da floração (figura 2). O grande número de botões coletados em setembro e outubro $\left(512,8\right.$ botões $\left./ \mathrm{m}^{2}\right)$ deveu-se, principalmente, a Ouratea semiserrata, cuja produção foi a maior entre as espécies (mais de 270 botões $/ \mathrm{m}^{2}$ ).

A fase de flores foi a mais representada, sendo que 70 entre as 90 espécies amostradas (78\% do total) foram coletadas e identificadas. Com picos no início do ano, encontram-se, por exemplo, Croton lundianus, Sclerolobium denudatum, Trigonia paniculata, Esenbeckia febrifuga e Pera glabrata. Algumas espécies, como Piptocarpha oblonga e Calyptranthes grandifolia, tiveram picos de floração no meio do ano, mas a maioria floresceu a partir de setembro.

Para algumas espécies foram amostradas flores masculinas e femininas (Alchornea sidifolia, Dalechampia tryphilla e Syagrus romanzoffiana), sendo as produções de flores masculinas maiores e estendidas por períodos mais longos.

Números elevados de flores foram encontrados nas peneiras, variando de aproximadamente 135 flo$\mathrm{res} / \mathrm{m}^{2}$, em julho, a 2994 flores $/ \mathrm{m}^{2}$, em novembro, num total de 8353,2 flores $/ \mathrm{m}^{2}$ (figura $1 \mathrm{~A}$ ). Em novembro mais de $86 \%$ do número de flores coletadas pertenciam a apenas quatro espécies (Mikania laevigata, M. micrantha, Alchornea sidifolia e Ouratea semiserrata). O pico de flores sucedeu ao de botões em um mês.

O número de espécies em flor por mês teve um aumento menos acentuado a partir de setembro, com 
46 espécies em flor em novembro. Na comunidade há espécies florescendo durante o ano todo, com aumento na primavera (figura 2).

Houve grande variação na quantidade de flores produzidas entre as espécies, sendo que para $37,1 \%$ delas foram coletadas menos de 5 flores $/ \mathrm{m}^{2} /$ ano. Frutificação - Os frutos imaturos foram separados numa categoria à parte, pois sua queda, por causa de danos ou produção excessiva, não pode ser considerada parte de uma estratégia real de frutificação (Jackson 1981). Observa-se um pico no aborto de frutos de novembro a janeiro, muito reduzido no inverno (figura 1B). A densidade de frutos imaturos coletados em um ano foi de $305,3 / \mathrm{m}^{2}$. A figura $2 \mathrm{traz}$ a distribuição do número de espécies que continham frutos imaturos por mês. Apenas 25 espécies tiveram frutos imaturos abortados. Foram coletadas flores de todas as espécies amostradas nesta fase, com exceção de Leandra purpurascens, cujas flores não foram encontradas, talvez por possuírem pétalas muito frágeis, que se decompõem rapidamente. Chuva de sementes - Do total de 90 espécies amostradas nas peneiras, 54 produziram propágulos no período de amostragem.
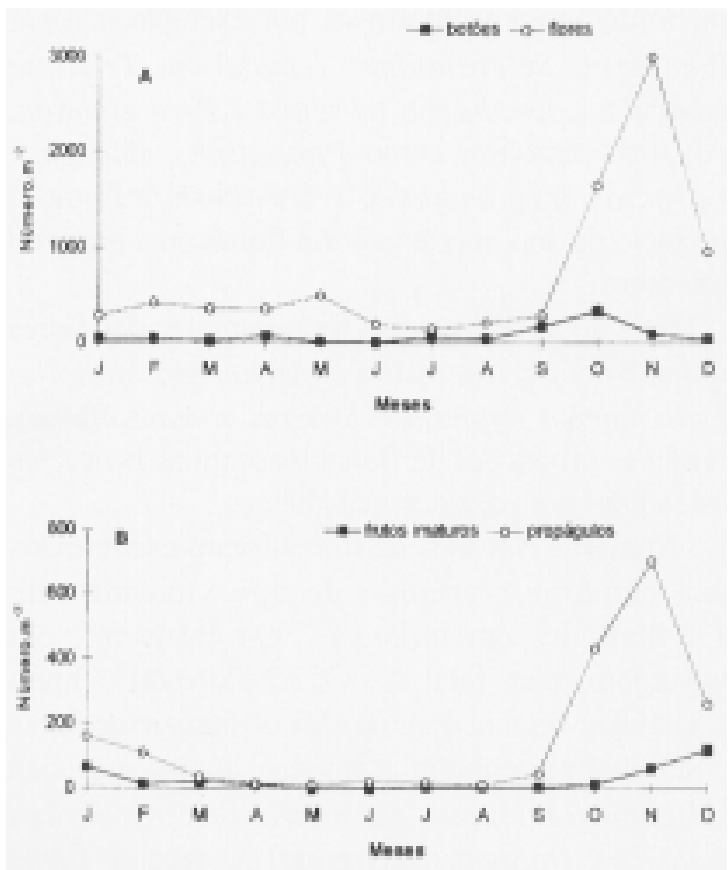

Figura 1. Número total de botões, flores (A), frutos imaturos e propágulos (B) amostrados mensalmente em peneiras coletoras no Parque do Estado, SP.
A distinção de propágulos de alguns grupos de espécies é muito difícil, como em Psychotria leiocarpa, P. suterella, P. sessilis e em Mikania cordifolia, $M$. laevigata e $M$. micrantha, o que não permite a análise da contribuição específica à chuva, sendo analisados como grupos de espécies (Mikania spp. e Psychotria spp.).

Croton lundianus e Pera glabrata produziram grandes quantidades de flores, mas não tiveram propágulo algum amostrado. As maiores produções de propágulos foram apresentadas por Mikania spp., Piptocarpha oblonga, Olyra micrantha, Miconia cabucu, Myrcia rostrata, Alchornea sidifolia, Psychotria spp. e Rapanea umbellata.

O pico de produção de propágulos (figura 1B) deu-se no período de outubro a fevereiro, ou seja, do final da estação seca até o meio da estação chuvosa. A densidade de propágulos coletados em um ano foi de $1804,2 / \mathrm{m}^{2}$.

Os valores em outubro e novembro deveram-se aos frutos de Compositae, principalmente dos gêneros Mikania e Piptocarpha, que contribuíram em novembro com quase $95 \%$ dos propágulos liberados.

O número de espécies liberando propágulos ao longo do ano mostra picos em novembro e dezembro, com 26 e 27 espécies, enquanto no restante do ano aquele número manteve-se entre 15 e 20 (figura 2).

Mais de $70 \%$ dos diásporos liberados pertenciam a cinco espécies de Compositae, que produziram grande quantidade de frutos pequenos e leves. Melastomataceae foi a segunda família mais abundante em propágulos, com a contribuição de apenas duas espécies. Muitas das espécies, mais de 43\%, contribuíram com apenas $2 \%$ dos propágulos liberados, não chegando o total a 41 propágulos $/ \mathrm{m}^{2}$. Formas de crescimento, síndromes de dispersão e estádios sucessionais - As características das 54 espécies que produziram propágulos estão apresentadas na tabela 1. Na chuva de sementes, a forma de crescimento predominante em espécies foi a arbórea, com 26, representando $48 \%$ do total.

As espécies arbóreas dispersaram suas sementes principalmente no período entre dezembro e março, ou seja, no período chuvoso (figura 3 ).

Entre os arbustos, $P$. oblonga e as espécies de Psychotria foram as que mais produziram sementes. As três espécies herbáceas que dispersaram 
Tabela 1. Composição florística e época de floração e frutificação conforme o material reprodutivo coletado em peneiras entre janeiro e dezembro de 1993, no Parque do Estado (São Paulo, SP). FC = formas de crescimento, Arv = arbórea, Arb = arbustiva, He = herbáceo, Li = liana, Hp = hemi-parasita, $\mathrm{ES}=$ estádios sucessionais, $\mathrm{Se}=$ secundária, $\mathrm{Cli}=$ clímace, $\mathrm{Sub}=$ sub-bosque, $\mathrm{SD}=$ síndromes de dispersão, Zoo = zoocoria, Ane $=$ anemocoria e Aut $=$ autocoria. $+=$ floração (botões e flores); o = frutos imaturos; $@=$ propágulos (frutos maduros e sementes).

\begin{tabular}{|c|c|c|c|c|c|c|c|c|c|c|c|c|c|c|c|}
\hline $\begin{array}{l}\text { Famílias } \\
\text { Espécies }\end{array}$ & $\mathrm{FC}$ & ES & $\mathrm{SD}$ & $\mathrm{J}$ & $\mathrm{F}$ & $\mathrm{M}$ & $\mathrm{A}$ & $\mathrm{M}$ & $\mathrm{J}$ & $\mathrm{J}$ & A & $\mathrm{S}$ & $\mathrm{O}$ & $\mathrm{N}$ & $\mathrm{D}$ \\
\hline \multicolumn{16}{|l|}{ ACANTHACEAE } \\
\hline Thunbergia alata Boj. & $\mathrm{Li}$ & - & Ane & $+@$ & + @ & $+\mathrm{o}$ & + & + & + & + & & + & + & $+o$ & $+@$ \\
\hline \multicolumn{16}{|l|}{ APOCYNACEAE } \\
\hline $\begin{array}{l}\text { Forsteronia velloziana (A. DC.) } \\
\text { Woods. } \\
\text { Prestonia coalita (Vell.) Woods. } \\
\text { Apocynaceae sp. }\end{array}$ & $\begin{array}{l}\mathrm{Li} \\
\mathrm{Li} \\
\mathrm{Li}\end{array}$ & $\begin{array}{l}- \\
-\end{array}$ & $\begin{array}{l}\text { Ane } \\
\text { Ane } \\
\text { Ane }\end{array}$ & $\begin{array}{l}+ \\
+\end{array}$ & $\begin{array}{l}+ \\
+\end{array}$ & $\begin{array}{l}+ \\
+\end{array}$ & $\begin{array}{c}+ \\
+@\end{array}$ & + & + & +o & $+@$ & $+@$ & $\begin{array}{l}+ \\
+@\end{array}$ & $\begin{array}{c}+ \\
+@ \\
+\end{array}$ & $\begin{array}{c}+ \\
+@\end{array}$ \\
\hline \multicolumn{16}{|l|}{ ASCLEPIADACEAE } \\
\hline $\begin{array}{l}\text { Tassadia subulata (Vell.) Font.\& } \\
\text { Schw. }\end{array}$ & $\mathrm{Li}$ & - & Ane & & & & & & & & + & & & & \\
\hline \multicolumn{16}{|l|}{ BIGNONIACEAE } \\
\hline Arrabidaea pulchella Bur. & $\mathrm{Li}$ & - & Ane & & & & & & & & & & & + @ & + @ \\
\hline Fridericia aff speciosa Mart. & $\mathrm{Li}$ & - & Ane & & & & & & @ & & & & $@$ & & \\
\hline Haplolophium bracteatum Cham. & $\mathrm{Li}$ & - & Ane & + & & & & & & & & & & + & + \\
\hline \multicolumn{16}{|l|}{ BORAGINACEAE } \\
\hline Cordia sellowiana Cham. & Arv & $\mathrm{Se}$ & Zoo & + & + & + & + & + & + & + & + & & + & & \\
\hline \multicolumn{16}{|l|}{ CELASTRACEAE } \\
\hline $\begin{array}{l}\text { Maytenus alaternoides (Reiss.) } \\
\text { Mart. }\end{array}$ & Arv & Sub & Zoo & +o@ & o@ & o@ & o@ & & @ & @ & & & + & + & +0 \\
\hline \multicolumn{16}{|l|}{ CLETHRACEAE } \\
\hline Clethra scabra Pers. & Arv & $\mathrm{Pi}$ & Aut & + & + & + & + & + & & & & + & + & & \\
\hline \multicolumn{16}{|l|}{ COMPOSITAE } \\
\hline $\begin{array}{l}\text { Gochnatia paniculata (Less.) } \\
\text { Cabrera }\end{array}$ & Arv & $\mathrm{Pi}$ & Ane & & & & & & & & & @ & & @ & $@$ \\
\hline Mikania cordifolia (Lf.) Willd. & $\mathrm{Li}$ & - & Ane & & & & & & & $+@$ & + @ & +@ & +@ & + @ & + @ \\
\hline Mikania laevigata Sch. Bip. & $\mathrm{Li}$ & - & Ane & + @ & + @ & + @ & +@ & +@ & + @ & $+@$ & + @ & $+@$ & $+@$ & + @ & + @ \\
\hline Mikania micrantha H.B.K. & $\mathrm{Li}$ & - & Ane & + @ & +@ & + @ & +@ & +@ & + @ & +@ & +@ & +@ & +@ & +@ & + @ \\
\hline Piptocarpha oblonga (Gard.) Baker & Arb & $\mathrm{Se}$ & Ane & + @ & + @ & + @ & +@ & + @ & $+@$ & + @ & + @ & $+@$ & + @ & + @ & + @ \\
\hline Compositae sp. & - & - & Ane & & & & & & & & & & + & + & \\
\hline \multicolumn{16}{|l|}{ CUNONIACEAE } \\
\hline Weinmannia discolor Gardn. & Arv & $\mathrm{Se}$ & Aut & & & + & & & & & & & + & + & + \\
\hline \multicolumn{16}{|l|}{ DILLENIACEAE } \\
\hline Davilla rugosa Poir & $\mathrm{Li}$ & - & Aut & $+@$ & & & + & $+@$ & $+@$ & $+@$ & + @ & +@ & $+@$ & +@ & +@ \\
\hline \multicolumn{16}{|l|}{ DIOSCOREACEAE } \\
\hline Dioscorea sp. & $\mathrm{Li}$ & - & Zoo & + & & & & & & & & & + & + & \\
\hline \multicolumn{16}{|l|}{ EUPHORBIACEAE } \\
\hline Alchornea sidifolia Muell. Arg. & Arv & $\mathrm{Se}$ & Zoo & +o@ & + & o@ & & & & & & + & + & + & +o@ \\
\hline Croton floribundus Spreng. & Arb & $\mathrm{Se}$ & Aut & $+@$ & +o@ & o@ & & $@$ & & & + & + & & + & +o@ \\
\hline $\begin{array}{l}\text { Croton lundianus (F. Diedrichs.) } \\
\text { Muell. Arg. }\end{array}$ & Arb & $\mathrm{Se}$ & Zoo & + & + & + & + & + & + & & + & & + & + & + \\
\hline Dalechampia tryphilla Lam. & $\mathrm{Li}$ & - & Zoo & +@ & +@ & +@ & +@ & +@ & + @ & $+@$ & +@ & +@ & +@ & +@ & +@ \\
\hline Pera glabrata (Schott.) Baill. & Arv & $\mathrm{Se}$ & Zoo & + & +@ & + @ & + & + & $+@$ & +o & + & + & + & + & $+@$ \\
\hline Euphorbiaceae sp. & - & - & - & + & + & + & + & & & & & & + & & \\
\hline \multicolumn{16}{|l|}{ GESNERIACEAE } \\
\hline Gesneriaceae sp. & $\mathrm{He}$ & - & Ane & & & & & & & & & & & + & \\
\hline \multicolumn{16}{|l|}{ GRAMINEAE } \\
\hline Chusquea sp. & $\mathrm{He}$ & $\mathrm{Se}$ & Zoo & & & + & + & + & & & & & & & \\
\hline
\end{tabular}




\begin{tabular}{|c|c|c|c|c|c|c|c|c|c|c|c|c|c|c|c|}
\hline $\begin{array}{l}\text { Famílias } \\
\text { Espécies } \\
\end{array}$ & $\mathrm{FC}$ & $\mathrm{ES}$ & $\mathrm{SD}$ & $\mathrm{J}$ & $\mathrm{F}$ & $\bar{M}$ & $\bar{A}$ & $\bar{M}$ & $\mathrm{~J}$ & $\mathrm{~J}$ & $\mathrm{~A}$ & $\mathrm{~S}$ & $\mathrm{O}$ & $\mathrm{N}$ & $\mathrm{D}$ \\
\hline Olyra micrantha H.B.K. & $\mathrm{He}$ & $\mathrm{Se}$ & Zoo & +o@ & o@ & o@ & @ & & & + & +0 & +o & +o@ & +o@ & +o@ \\
\hline Oplismenus hirtellus (L.) Beauv. & $\mathrm{He}$ & Sub & Zoo & + & + & + & + & & & & & & & & + \\
\hline Panicum glutinosum Swartz. & $\mathrm{He}$ & Sub & Zoo & $@$ & @ & @ & & & & & & & & & \\
\hline Pennisetum purpureum Schumach & $\mathrm{He}$ & $\mathrm{Pi}$ & Ane & & & & & & & $@$ & @ & @ & & & \\
\hline $\begin{array}{l}\text { GUTTIFERAE } \\
\text { Clusia criuva Camb. } \\
\text { Rheedia gardneriana } \text { Planch. \& }\end{array}$ & Arv & $\mathrm{Se}$ & Zoo & + & + & + & & & & & & & & & + \\
\hline Triana & Arv & $\mathrm{Se}$ & Zoo & + & & + & + & & & & & + & + & $+@$ & + \\
\hline $\begin{array}{l}\text { LAURACEAE } \\
\text { Ocotea pulchella (Nees.) Mez. } \\
\text { LECYTHIDACEAE }\end{array}$ & Arv & $\mathrm{Se}$ & Zoo & & & & & & & + & & & & & \\
\hline $\begin{array}{l}\text { Cariniana estrellensis (Raddi) } \\
\text { Kuntze }\end{array}$ & Arv & Cli & Ane & & & & & @ & @ & @ & @ & @ & @ & & \\
\hline Cariniana legalis (Mart.) Kuntze & Arv & $\mathrm{Cli}$ & Ane & & @ & @ & @ & $@$ & $@$ & & & & & & \\
\hline LEGUMINOSAE & & & & & & & & & & & & & & & \\
\hline $\begin{array}{l}\text { Andira anthelmia (Vell.) Macbr. } \\
\text { Machaerium angustifolium Vog. }\end{array}$ & $\begin{array}{l}\text { Arv } \\
\text { Arv }\end{array}$ & $\begin{array}{l}\mathrm{Cli} \\
\mathrm{Se}\end{array}$ & $\begin{array}{l}\text { Zoo } \\
\text { Ane }\end{array}$ & $\begin{array}{c}+ \\
\text { o@ }\end{array}$ & $\begin{array}{l}+ \\
+\end{array}$ & & + & & + & + & & & & + & $\begin{array}{l}+ \\
+\end{array}$ \\
\hline Sclerolobium denudatum Vog. & Arv & Cli & Ane & +o & +0 & +o@ & +o@ & + & & & + & +o@ & + & +@ & +o@ \\
\hline $\begin{array}{l}\text { Senna macranthera (Collad.) Irwin } \\
\& \text { Barneby }\end{array}$ & Arv & $\mathrm{Se}$ & Zoo & @ & & + & & & & & & & & & \\
\hline $\begin{array}{l}\text { Leguminosae sp. } \\
\text { LORANTHACEAE }\end{array}$ & - & - & - & & & & @ & @ & @ & & & & & & \\
\hline $\begin{array}{l}\text { Struthanthus concinnus Mart. } \\
\text { MALPIGHIACEAE }\end{array}$ & Hp & - & Zoo & & & + & & & & & & & & & \\
\hline $\begin{array}{l}\text { Mascagnia sepium (Adr. Juss.) } \\
\text { Griseb }\end{array}$ & $\mathrm{Li}$ & - & Ane & o@ & & & & & & o & & & & @ & +o@ \\
\hline $\begin{array}{l}\text { Tetrapterys crebriflora Adr. Juss. } \\
\text { Malpighiaceae sp. }\end{array}$ & $\begin{array}{c}\mathrm{Li} \\
-\end{array}$ & - & $\begin{array}{c}\text { Ane } \\
-\end{array}$ & & & & + & + & + & + & + & $\begin{array}{c}+ \\
+0\end{array}$ & $\begin{array}{c}+@ \\
0\end{array}$ & +@ & +@ \\
\hline $\begin{array}{l}\text { MELASTOMATACEAE } \\
\text { Leandra purpurascens Cogn. }\end{array}$ & Arb & $\mathrm{Se}$ & Zoo & o@ & o & o & & & & & & & & o & \\
\hline Miconia cabucu Hoehne & Arv & $\mathrm{Se}$ & Zoo & +o@ & @ & @ & @ & $@$ & $@$ & @ & @ & $+@$ & $+@$ & +o@ & +o@ \\
\hline Miconia pyrifolia Naud. & Arv & $\mathrm{Se}$ & Zoo & & & + & + & + & + & + & & + & & & \\
\hline $\begin{array}{l}\text { Tibouchina mutabilis Cogn. } \\
\text { MYRSINACEAE }\end{array}$ & Arv & $\mathrm{Pi}$ & Aut & & & & & & & & & & & + & + \\
\hline $\begin{array}{l}\text { Conomorpha peruviana A. DC. } \\
\text { Rapanea umbellata (Mart.) Mez. }\end{array}$ & $\begin{array}{l}\text { Arv } \\
\text { Arv }\end{array}$ & $\begin{array}{l}\mathrm{Se} \\
\mathrm{Se}\end{array}$ & $\begin{array}{l}\text { Zoo } \\
\text { Zoo }\end{array}$ & $@$ & $\begin{array}{l}+ \\
@\end{array}$ & $\begin{array}{l}+ \\
@\end{array}$ & + & $\begin{array}{l}+ \\
@\end{array}$ & $\begin{array}{l}+ \\
@\end{array}$ & @ & & $\begin{array}{l}+ \\
@\end{array}$ & + & & $\begin{array}{l}+ \\
@\end{array}$ \\
\hline $\begin{array}{l}\text { MYRTACEAE } \\
\text { Calyptranthes grandifolia Berg. }\end{array}$ & Arv & Sub & Zoo & @ & @ & & $+@$ & +@ & + & + & + & +o@ & +o@ & +o@ & +o@ \\
\hline Myrcia obtecta (Berg.) Kiaersk. & Arv & $\mathrm{Cli}$ & Zoo & & & & & & & & & + & + & + & + \\
\hline Myrcia rostrata DC. & Arv & $\mathrm{Se}$ & Zoo & +o@ & +o@ & + & & & & & + & + & + & +0 & +o@ \\
\hline Psidium cattleyanum Sab. & Arv & $\mathrm{Se}$ & $\mathrm{Z}$ & & & & & & @ & @ & @ & & & & \\
\hline $\begin{array}{l}\text { Myrtaceae sp. } \\
\text { NYCTAGINACEAE }\end{array}$ & Arv & - & Zoo & & & & @ & & & & @ & & @ & & \\
\hline $\begin{array}{l}\text { Guapira opposita (Vell.) Reitz. } \\
\text { OCHNACEAE }\end{array}$ & Arv & $\mathrm{Se}$ & Zoo & & & & & & & + & + & + & + & + & \\
\hline $\begin{array}{l}\text { Ouratea semiserrata (Mart. et } \\
\text { Nees.) Engl. }\end{array}$ & Arv & Sub & Zoo & +0 & + & $+@$ & + @ & + & & & + & + & + & +o & +o@ \\
\hline PALMAE & & & & & & & & & & & & & & & \\
\hline $\begin{array}{l}\text { Syagrus romanzoffiana (Cham.) } \\
\text { Glassman }\end{array}$ & Arv & $\mathrm{Se}$ & Zoo & & $+@$ & +@ & + & + & + & + & + & + & + & + & + \\
\hline
\end{tabular}




\begin{tabular}{|c|c|c|c|c|c|c|c|c|c|c|c|c|c|c|c|}
\hline $\begin{array}{l}\text { Famílias } \\
\text { Espécies }\end{array}$ & $\mathrm{FC}$ & ES & SD & $\mathrm{J}$ & $\mathrm{F}$ & M & A & M & $\mathrm{J}$ & $\mathrm{J}$ & A & $\mathrm{S}$ & $\mathrm{O}$ & $\mathrm{N}$ & $\mathrm{D}$ \\
\hline \multicolumn{16}{|l|}{ PIPERACEAE } \\
\hline $\begin{array}{l}\text { Piper caldense C. DC. } \\
\text { POLYGALACEAE }\end{array}$ & Arb & Sub & Zoo & + & + & + & & & & + & & + & + & + & + \\
\hline $\begin{array}{l}\text { Diclidanthera laurifolia Mart. } \\
\text { Securidaca tomentosa St. Hill. }\end{array}$ & $\begin{array}{c}\text { Arv } \\
\mathrm{Li}\end{array}$ & $\begin{array}{c}\text { Sub } \\
-\end{array}$ & $\begin{array}{l}\text { Zoo } \\
\text { Ane }\end{array}$ & & & & & & & & & & + & +0 & $\begin{array}{c}+0 @ \\
+\end{array}$ \\
\hline $\begin{array}{l}\text { POLYGONACEAE } \\
\text { Coccoloba arborescens (Vell. } \\
\text { How. }\end{array}$ & Arv & $\mathrm{Se}$ & Zoo & & & + & & + & + & + & + & + & + & + & \\
\hline \multicolumn{16}{|l|}{ RUBIACEAE } \\
\hline Amaioua guianensis Aubl. & Arv & $\mathrm{Se}$ & Zoo & + & $+@$ & + & + & & & & & & & & + \\
\hline Palicourea marcgravii St. Hill. & Arv & $\mathrm{Pi}$ & Zoo & + & + & + & + & & $+@$ & +@ & & $+@$ & & & + \\
\hline $\begin{array}{l}\text { Psychotria leiocarpa Cham. et } \\
\text { Schl. }\end{array}$ & Arb & Sub & Zoo & +@ & @ & $@$ & @ & & @ & @ & @ & $+@$ & +@ & + @ & $+@$ \\
\hline $\begin{array}{l}\text { Psychotria sessilis (Vell.) } \\
\text { Muell. Arg. }\end{array}$ & Arb & Sub & Zoo & & $@$ & + & & + & @ & @ & @ & @ & @ & $+@$ & @ \\
\hline Psychotria tenerior Muell. Arg. & Arb & Sub & Zoo & & + & & & & + & & & + & & + & \\
\hline $\begin{array}{l}\text { Rudgea gardnerioides } \\
\text { (Cham.) Muell. Arg }\end{array}$ & Arv & Sub & Zoo & & & $@$ & & & & & @ & & & & \\
\hline $\begin{array}{l}\text { Rudgea jasminoides (Cham.) } \\
\text { Muell. Arg. }\end{array}$ & Arv & Sub & Zoo & & & $+@$ & + @ & & @ & @ & & & & + & +0 \\
\hline Rubiaceae sp. 1 & - & - & - & + & & + & + & + & + & + & & + & & + & + \\
\hline Rubiaceae sp. 2 & - & - & - & + & + & & & + & + & + & + & + & + & + & + \\
\hline \multicolumn{16}{|l|}{ RUTACEAE } \\
\hline $\begin{array}{l}\text { Angostura pentandra } \\
\text { (St. Hill.) Albuquerque }\end{array}$ & Arv & Sub & Zoo & & + & + & + & + & + & & & + & + & +0 & \\
\hline $\begin{array}{l}\text { Esenbeckia febrifuga } \\
\text { (St. Hill.) Adr. Juss. }\end{array}$ & Arv & Sub & Aut & +0 & + & + & + & $+@$ & + & + & + & + & & & \\
\hline Rutaceae sp. & Arv & - & - & & & & & & & & & & + & & + \\
\hline \multicolumn{16}{|l|}{ SAPINDACEAE } \\
\hline Cupania emarginata $\mathrm{Camb}$. & Arv & $\mathrm{Se}$ & Zoo & & +0 & $+\mathrm{o}$ & +o & & & @ & @ & +o@ & $+@$ & + @ & + \\
\hline Paullinia seminuda Radlk. & $\mathrm{Li}$ & - & Ane & +o & +0 & + & + & + & + & & & + & +0 & +@ & +o \\
\hline Serjania gracilis Radlk. & $\mathrm{Li}$ & - & Ane & @ & @ & & & & & & & + & $+@$ & @ & @ \\
\hline SMILACACEAE & & & & & & & & & & & & & & & \\
\hline $\begin{array}{l}\text { Smilax elastica Griseb. } \\
\text { SOLANACEAE }\end{array}$ & $\mathrm{Li}$ & - & Zoo & & & & & + & + & + & + & + & & & \\
\hline Solanum erianthum D. Don. & Arv & $\mathrm{Se}$ & Zoo & & @ & @ & & & & @ & $+@$ & + & $+@$ & +o@ & + \\
\hline Solanum inaequale Vell. & Arv & $\mathrm{Pi}$ & Zoo & +o@ & & + & $+@$ & +o@ & @ & + @ & +o@ & @ & +@ & +@ & @ \\
\hline $\begin{array}{l}\text { Solanum swartzianum Roem } \\
\text { Schult. }\end{array}$ & Arv & $\mathrm{Pi}$ & Zoo & & + & + & & + & & & & & & + & \\
\hline TRIGONIACEAE & & & & & & & & & & & & & & & \\
\hline Trigonia paniculata Warm. & Arb & $\mathrm{Se}$ & Ane & +0 & +o & +o & +o & +o@ & +o@ & $+@$ & +o@ & $+@$ & +o@ & $+@$ & $+@$ \\
\hline $\begin{array}{l}\text { VALERIANACEAE } \\
\text { Valeriana scandens } \mathrm{L} .\end{array}$ & $\mathrm{Li}$ & - & Zoo & & & & & & & & @ & @ & @ & @ & \\
\hline VIOLACEAE & & & & & & & & & & & & & & & \\
\hline $\begin{array}{l}\text { Anchietea pyrifolia } \\
\text { (Mart.) Don. }\end{array}$ & Arb & $\mathrm{Pi}$ & Ane & & & & & & & + & + & + & @ & @ & \\
\hline INDETERMINADAS & & & & & & & & & & & & & & & \\
\hline Indeterminada 1 & - & - & Zoo & & & & & & & & & @ & @ & & \\
\hline Indeterminada 2 & - & - & Zoo & & & & & & & & & & & @ & @ \\
\hline Indeterminada 3 & - & - & Zoo & & & $@$ & @ & @ & @ & & & & & & \\
\hline Indeterminada 4 & - & - & Zoo & & @ & & & & & & & & & & $@$ \\
\hline
\end{tabular}


sementes nos coletores foram de Gramineae, com predomínio de Olyra micrantha, que ocupa quase todo o sub-bosque da mata.

A percentagem de lianas foi alta, com $22 \%$ das espécies amostradas. Entre as lianas, as espécies de Mikania foram as que dispersaram mais diásporos. As sementes de Mikania, tipicamente anemocóricas, possuem dispersão bastante facilitada, tendo sido amostradas em quase todas as peneiras em outubro e novembro.

Tanto arbustos, quanto herbáceas e lianas, dispersaram sementes predominantemente no final do ano, entre outubro e dezembro, alternando os meses de maior produção entre elas, com os arbustos e as lianas em novembro e as herbáceas em dezembro (figura 3). Para as herbáceas, a grande produção de dezembro deveu-se a Olyra micrantha.

Quanto ao número de espécies relacionadas às formas de crescimento, há um padrão semelhante àquele do número de propágulos liberados (figura 4), com exceção das herbáceas, que foram as menos amostradas entre as formas de crescimento (apenas duas espécies), o que é compreensível devido à metodologia utilizada. Plantas com alturas muito baixas possuem chances menores de terem propágulos amostrados nas peneiras. Assim sendo, somente aquelas herbáceas que estivessem próximas às peneiras poderiam ser amostradas, como foi o caso de $O$. micrantha, que estava ao redor de quase todas elas.

As lianas apresentaram o maior número de propágulos produzidos ao longo do ano (873,2 prop./ $\mathrm{m}^{2}$, tabela 2) vindo, a seguir os arbustos, com 502,9 prop. $/ \mathrm{m}^{2}$.

Entre as síndromes de dispersão, 59\% das espécies são zoocóricas e 33\% delas apresentam síndrome de anemocoria. Dividindo-se as espécies por síndrome de dispersão, podem ser separados os períodos de maior frutificação e dispersão de sementes, como mostra a figura 5 .

O pico de dispersão dos propágulos das espécies anemocóricas deu-se em outubro e novembro. Normalmente as chuvas iniciam-se em outubro, mas no ano de 1993 houve um período de seca anormal em novembro. Pode-se dizer, portanto, que os diásporos anemocóricos foram liberados no final de estação seca e início de estação chuvosa.

O pico de dispersão dos propágulos das espécies zoocóricas deu-se entre dezembro e fevereiro, ou seja, no verão, época de chuvas intensas.

Em relação às espécies autocóricas, devido ao pequeno número de propágulos amostrados, não foi

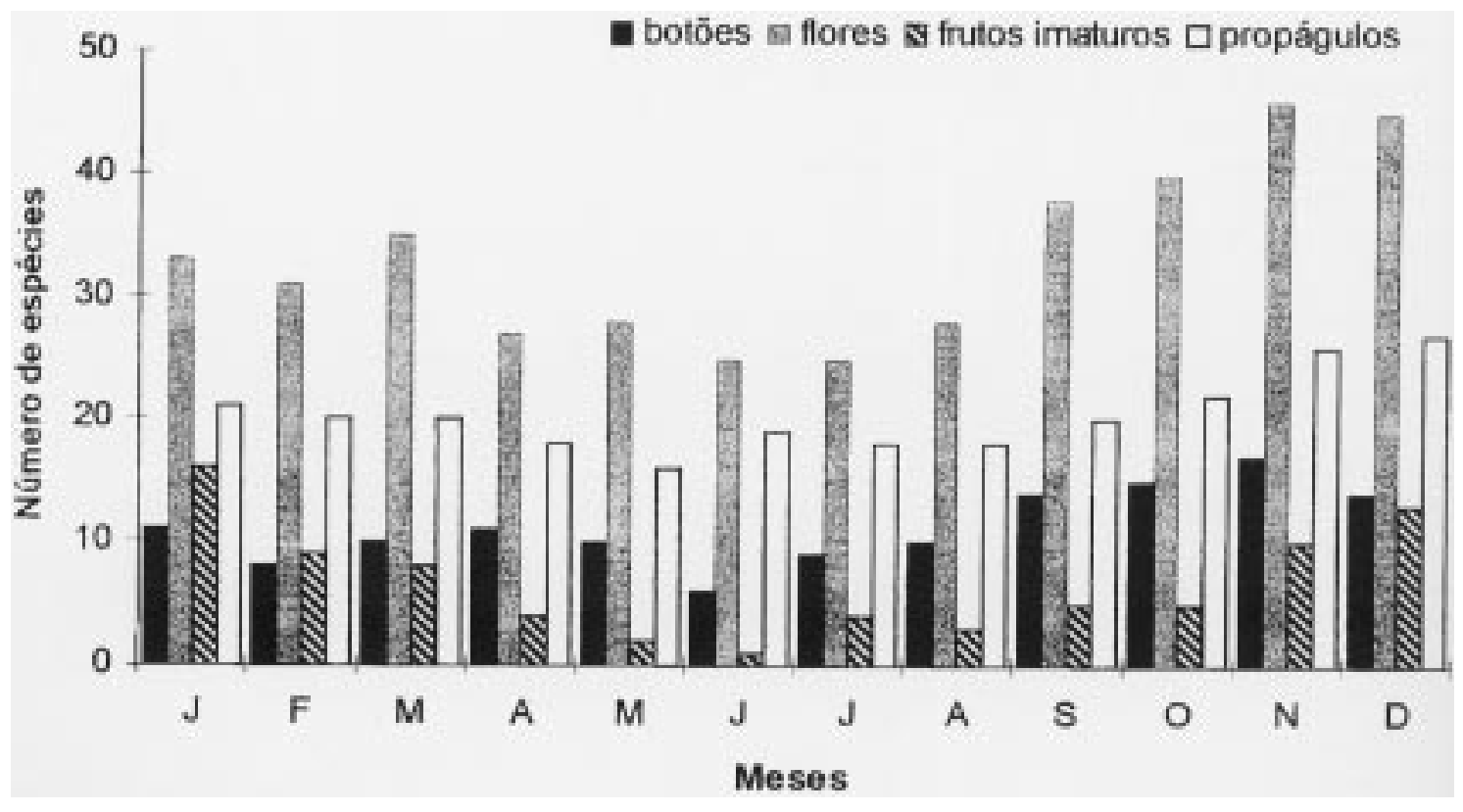

Figura 2. Número de espécies amostrados mensalmente em peneiras coletoras no Parque do Estado, SP. 
possível determinar uma época predominante para dispersão, já que os dois picos observados, em julho e em novembro, deveram-se a D. rugosa.

Há um ligeiro aumento no número de espécies zoocóricas sendo dispersas de dezembro a março (figura 6) e uma queda substancial em maio, enquanto nos demais meses o número manteve-se praticamente constante. O número de espécies zoocóricas dispersando foi maior que o de espécies com outras síndromes em todos os meses. O número de espécies anemocóricas em dispersão aumentou no final da estação seca e início da chuvosa, mantendo-se ao redor de cinco no resto do ano. O número de autocóricas em dispersão manteve-se constante.

As espécies anemocóricas dispersaram a maior parte dos propágulos amostrados (74,8\%, tabela 2), devido às várias lianas e espécies de Compositae. Das 18 espécies anemocóricas amostradas nove (50\%) eram lianas, cinco (28\%) árvores, três (17\%) arbustos e uma (5\%) herbácea.

Em relaçao à categoria sucessional, $90 \%$ dos propágulos foram produzidos por espécies secundárias $\left(821,6\right.$ prop. $\left.\mathrm{m}^{2}\right), 7,5 \%$ pelas espécies do subbosque $(67,1$ prop./m²) e uma pequena fração pelas espécies clímaces $\left(4,6\right.$ prop. $\left.\mathrm{m}^{2}\right)$ e pioneiras
(11,0 prop. $\left./ \mathrm{m}^{2}\right)$. As lianas foram excluídas desta análise, por serem de difícil determinação quanto à sucessão.

\section{Discussão}

Padrões de floração e de frutificação - Os dados fenológicos obtidos indicaram padrões sazonais de floração e de frutificação para a comunidade.

O início da floração coincidiu com o início das chuvas em setembro, atingindo o pico em novembro. Segundo Opler et al. (1976), o fotoperíodo é o maior responsável pela indução do desenvolvimento floral, mas as primeiras chuvas desencadeiam os estádios finais do desenvolvimento, levando a uma seqüência de anteses sincronizadas.

Wright \& van Schaik (1994) verificaram que, em sete florestas tropicais distantes entre si, a produção de flores em espécies arbóreas coincidiu com o pico de irradiância, quando a água estava mais disponível.

O pico de floração antes da época de chuvas fortes, que em São Paulo concentram-se de janeiro a março, é vantajoso, já que chuvas fortes podem danificar as flores e também prejudicar a atividade dos polinizadores (Jackson 1978).

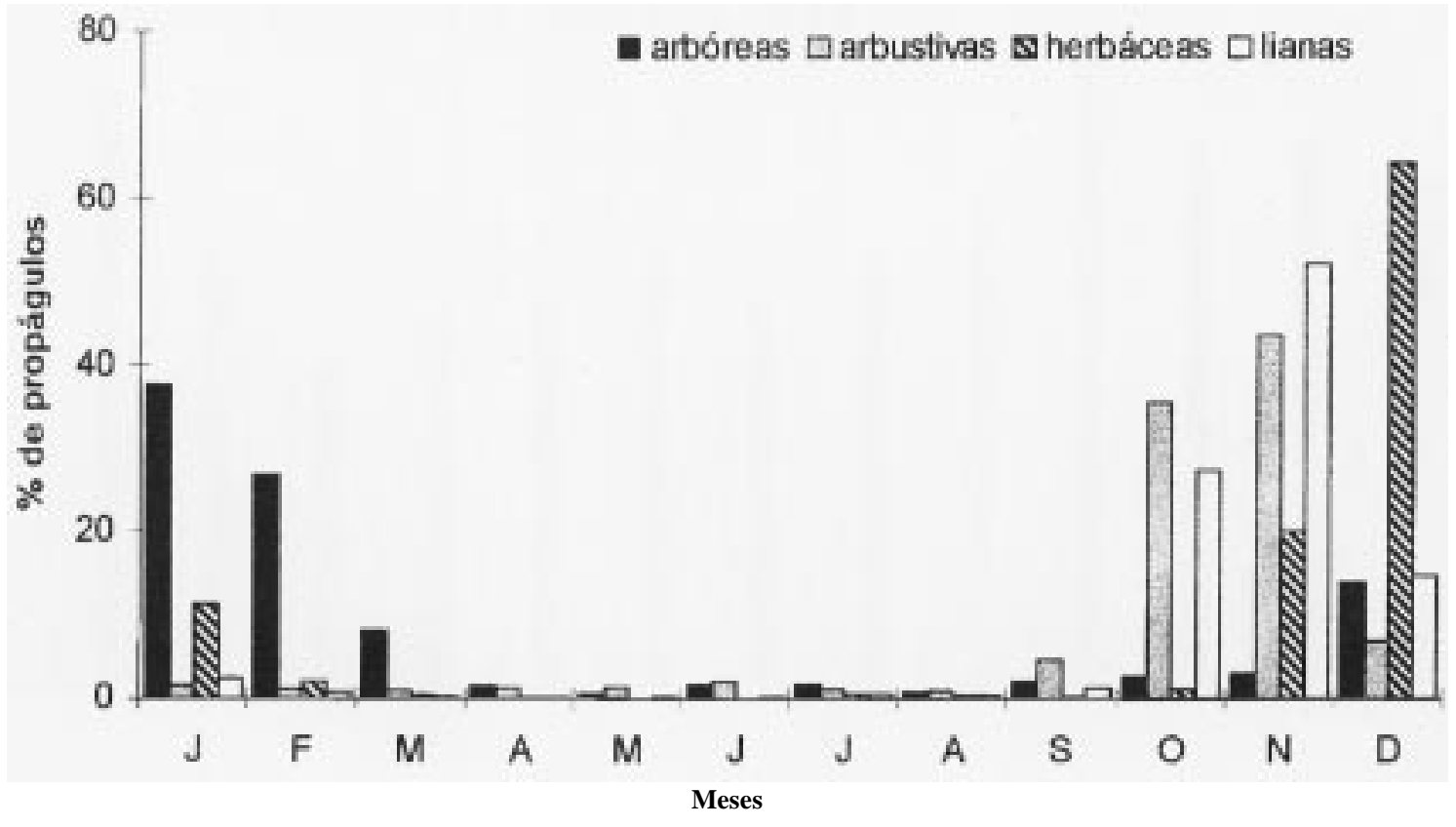

Figura 3. Porcentagem mensal de propágulos das diferentes formas de crescimento, amostrados em peneiras coletoras no Parque do Estado, SP. 
Tabela 2. Distribuição do número de espécies $(\mathrm{N})$ e da densidade de propágulos (propágulos $/ \mathrm{m}^{2}$ ) nas diversas formas de crescimento e síndromes de dispersão, no Parque do Estado, SP.

\begin{tabular}{lrrrrr}
\hline Características & \multicolumn{2}{c}{ Espécies } & & \multicolumn{2}{c}{ Propágulos } \\
\cline { 2 - 3 } \cline { 5 - 6 } \cline { 5 - 6 } Formas de crescimento & $\mathrm{N}$ & $\%$ & & Dens. & $\%$ \\
$\quad$ arbórea & 26 & 48,1 & & 331,6 & 18,6 \\
arbustiva & 8 & 14,8 & & 502,9 & 28,3 \\
$\quad$ herbácea & 3 & 5,5 & & 70,2 & 3,9 \\
liana & 12 & 22,3 & & 873,2 & 49,0 \\
$\quad$ indeterminada & 5 & 9,3 & & 2,9 & 0,2 \\
Síndromes de dispersão & & & & \\
$\quad$ anemocoria & 18 & 33,3 & & 1331,7 & 74,8 \\
$\quad$ autocoria & 3 & 5,5 & & 16,3 & 0,9 \\
$\quad$ zoocoria & 32 & 59,3 & & 432,3 & 24,3 \\
$\quad$ indeterminada & 1 & 1,9 & & 0,5 & 0,03 \\
\hline
\end{tabular}

O mesmo padrão de floração foi observado por Morellato et al. (1989) em duas florestas no interior do estado, próximas ao município de São Paulo. Estes autores, no entanto, não verificaram picos de frutificação sobrepostos aos de floração, como foi observado neste estudo. Um dos motivos que pode ter contribuído para esta diferença é que eles amostraram apenas espécies arbóreas. Matthes et al. (1988) observaram, também, um pico de floração para espécies arbóreas em setembro e outubro no Bosque dos Jequitibás, Campinas. Segundo Rossi (1994), na reserva da Cidade Universitária, também em São Paulo, muitas das espécies florescem entre agosto e dezembro. O pico de frutificação para espécies que produzem frutos carnosos se dá entre outubro e dezembro e para as espécies de frutos secos, durante a época seca.

A pronunciada agregação nos eventos fenológicos observada pode, segundo Murali \& Sukumar (1994), ocorrer com freqüência em florestas tropicais sazonais. Para as espécies estudadas, as épocas de floração e de frutificação sobrepuseram-se, demonstrando o rápido desenvolvimento do fruto. $\mathrm{O}$ início da maturação dos frutos é determinado principalmente por fatores internos, que controlam a sua taxa de desenvolvimento. Estímulos ambientais influenciam apenas indiretamente, inibindo ou estimulando o metabolismo (Rathcke \& Lacey 1985).

Separando-se as espécies em relação ao tipo de fruto produzido, para a maioria das espécies com frutos secos e propágulos plumosos, os períodos de

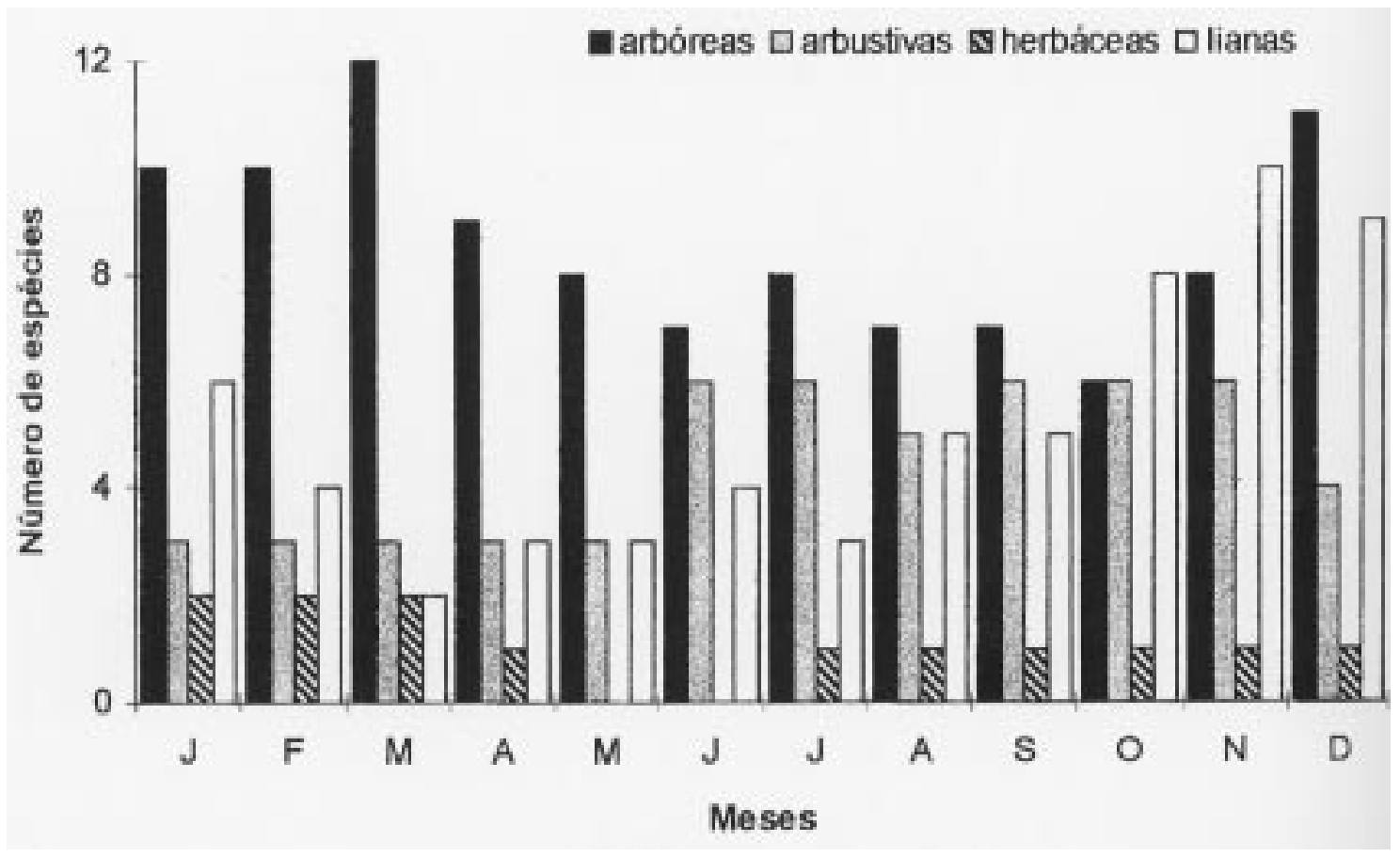

Figura 4. Número de espécies que tiveram propágulos amostrados mensalmente, separadas por forma de crescimento, no Parque do Estado, SP. 
floração e de frutificação foram bastante coincidentes, e para as espécies com frutos carnosos, o pico de frutificação foi posterior ao de floração. Isto se dá porque o desenvolvimento de frutos carnosos é mais lento do que o de frutos com propágulos plumosos.

Um estudo sobre a produção de serapilheira na mata estudada (Teixeira et al. 1992) demonstrou que

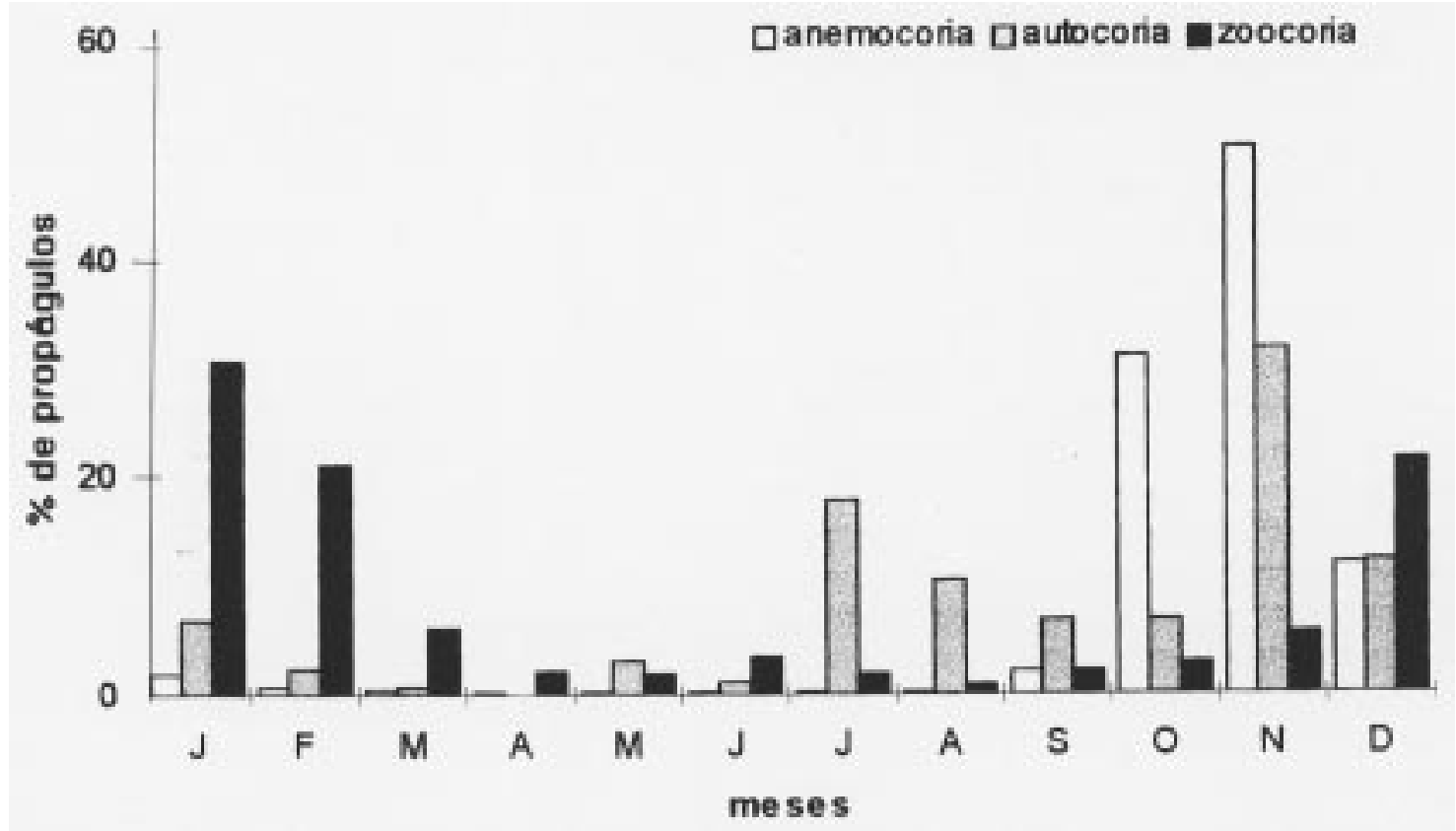

Figura 5. Porcetangem mensal de propágulos das diferentes síndromes de dispersão, amostrados em peneiras coletoras no Parque do Estado, SP.

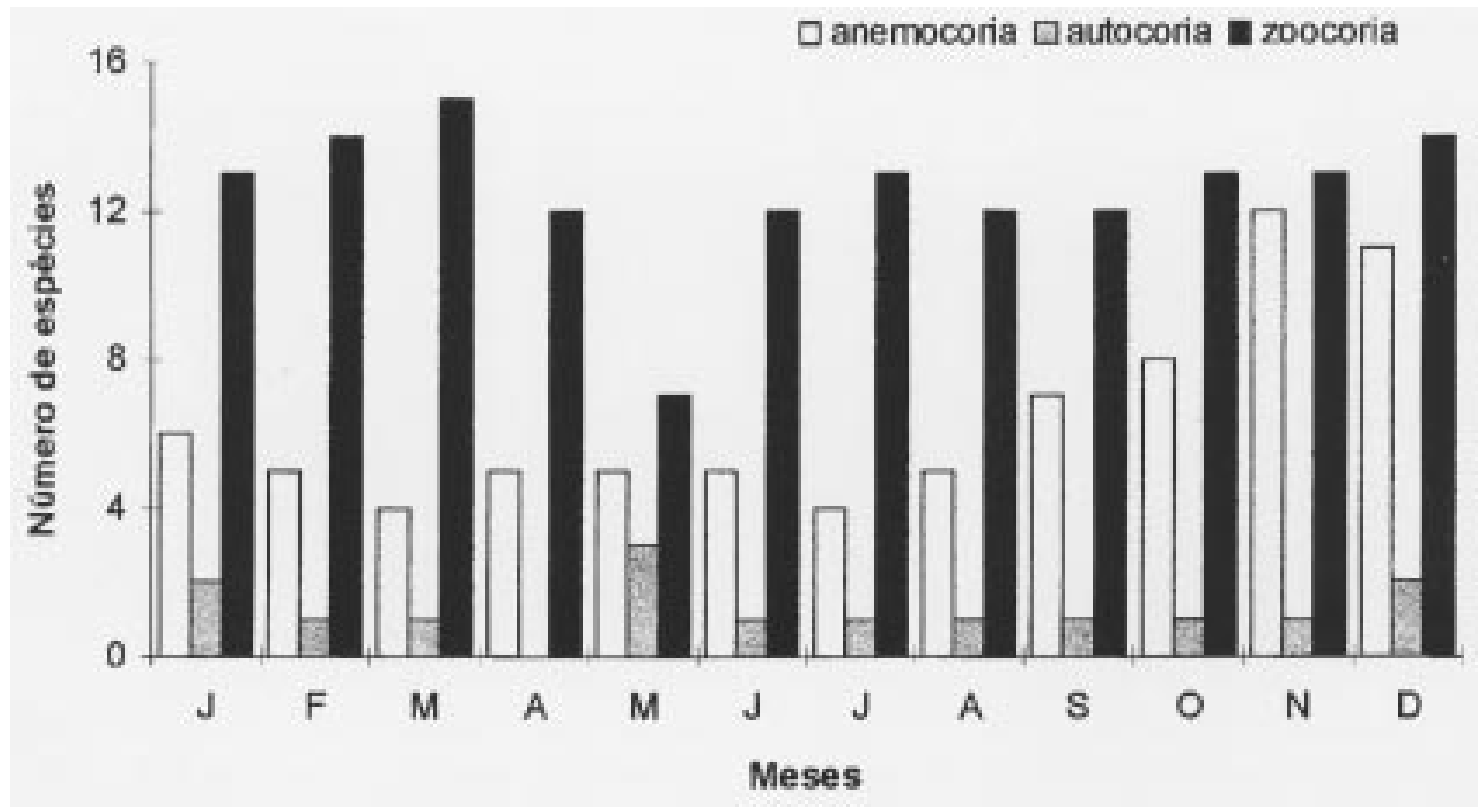

Figur 6. Número de espécies que tiveram propágulos amostrados mensalmente, separadas por síndrome de dispersão, no Parque do Estado, SP. 
a maior quantidade de estruturas reprodutivas (flores, frutos e sementes) foi produzida entre outubro e janeiro, o que coincide com os dados obtidos neste trabalho.

Para a maioria das espécies, as épocas de floração e de frutificação citadas por Hoehne et al. (1941) e pelas publicações da "Flora Fanerogâmica do Parque Estadual das Fontes do Ipiranga" (segundo Melhem et al. 1981) coincidem com as aqui obtidas. As fases aqui apresentadas, no entanto, são mais extensas do que as mostradas por eles, o que é compreensível, uma vez que tanto o levantamento realizado por Hoehne, quanto o da Flora são florísticos.

Em outros trabalhos efetuados em fragmentos de matas na cidade de São Paulo (Rossi 1994, Barbosa et al. 1977/78, Baitello et al. 1983/85), as espécies amostradas neste estudo, também amostradas por eles, nem sempre apresentaram períodos de floração ou de frutificação coincidentes. Isto demonstra que, entre as espécies, os padrões fenológicos podem variar de local para local, como salientado por Newstrom et al. (1994).

No caso de flores de sexos separados, foi observado que as flores femininas foram produzidas por período mais curto do que as masculinas. Esta diferença pode estar relacionada aos papéis diferentes que possuem e a custos metabólicos distintos para a produção de estruturas reprodutivas.

Segundo a classificação de Gentry (1974 apud Rathcke \& Lacey 1985), espécies como Alchornea sidifolia, Paulinia seminuda e Ouratea semiserrata produzem grande quantidade de flores em curto espaço de tempo (flowering mass), enquanto espécies como Dalechampia tryphilla, Esenbeckia febrifuga e Syagrus romanzoffiana possuem floração do tipo "steady-state", caracterizada pela produção de poucas flores por dia por um período extenso. Este tipo de floração pode ser encontrado em muitas espécies do sub-bosque da floresta (Rathcke \& Lacey 1985).

Para algumas espécies, tais como Croton lundianus, Pera glabrata, Ouratea semiserrata, Paullinia seminuda e Trigonia paniculata, a floração apresentou uma distribuição assimétrica, ou seja, começou abruptamente com a produção de um grande número de flores e depois cessou aos poucos. Esta pode ser uma estratégia para aumentar a atração dos polinizadores, que continuariam visitando suas flores mesmo após o declínio na produção (Rathcke \& Lacey 1985).

Na comunidade há espécies florescendo durante o ano todo, com aumento na primavera. Este aumento foi acompanhado pela densidade de flores produzidas. Pode-se considerar que quando menos espécies estão em flor, a quantidade de flores de uma espécie necessária para atrair polinizadores é menor do que quando muitas espécies estão florescendo. Neste último caso, o esforço reprodutivo para assegurar a polinização deve ser maior, aumentando a densidade de flores na comunidade.

Foram produzidas muito mais flores do que frutos pelas diversas espécies amostradas. Isto já era esperado, uma vez que o esforço metabólico necessário para a maturação de um fruto é muito maior do que para a produção de flores (Rathcke \& Lacey 1985, Primack 1987). Além disso, nem todas as flores são polinizadas e conseguem desenvolver o fruto, de forma que muitas perdas ocorrem durante o processo.

O método de coleta utilizado não registra frutos que são consumidos quando ainda presos à planta (Chapman et al. 1994, Greene \& Johnson 1994, White 1994). Apenas estas razões, no entanto, não podem ser responsáveis pelo fato de algumas espécies não terem apresentado frutos coletados durante o período.

White (1994) cita entre as causas prováveis para a ausência de frutificação, a perda de frutos por consumo e a presença de doenças que afetam o seu desenvolvimento. Estas razões poderiam ser observadas, por exemplo, em Angostura pentandra, que apresentou somente frutos imaturos amostrados.

A fragmentação da vegetação também pode alterar a produção de sementes de determinadas espécies, através de mudanças nas interações animal-planta, afetando a polinização, ou pelo aumento da endogamia, causada pela diminuição do fluxo gênico. Segundo Aizen \& Feinsinger (1994), a polinização e a produção de sementes diminuem com o aumento da fragmentação.

Segundo Richards (1952), no entanto, a maioria das árvores dos estratos superiores produz sementes em grande quantidade pelo menos uma vez a cada três anos, podendo, neste intervalo, florescer sem que as sementes sejam produzidas ou amadurecidas. Desta forma, pode ter ocorrido ausência de frutos 
nestas populações apenas no período amostrado, o que torna necessários estudos mais longos para que outras considerações sejam feitas.

Chuva de sementes - A época de amadurecimento dos frutos deve coincidir com o período que apresenta as melhores condições para o sucesso da dispersão e o estabelecimento de plântulas (Rathcke \& Lacey 1985). Para a comunidade estudada, a época preferencial para a liberação de sementes foi do final da estação seca até o meio da estação chuvosa.

As sementes coletadas foram, em grande parte, pequenas. $\mathrm{O}$ tamanho das sementes amostradas esteve, aproximadamente, entre 0,2 e 2,4 cm. As menores foram dos gêneros Solanum e Miconia e as maiores de Syagrus, Cupania e Rudgea. Espécies características de hábitats abertos ou estádios iniciais da sucessão, tendem a apresentar sementes menores do que aquelas características de hábitats fechados e sombreados e de associações sucessionais tardias (Salisbury 1974 e Baker 1972 apud Foster \& Janson 1985).

O rápido desenvolvimento observado dos frutos também está relacionado aos seus pequenos tamanhos, já que frutos grandes requerem períodos de tempo mais longos para a maturação (Primack 1987).

O peso da semente pode influenciar diretamente muitos aspectos da estratégia reprodutiva da espécie, tais como onde a semente pode germinar e crescer, o número de sementes a ser produzido, o tempo de maturação do fruto e a sua forma de dispersão (Foster \& Janson 1985). Sementes pequenas podem ser produzidas em maior número e possuem a vantagem da dispersão mais facilitada para locais apropriados, possuindo, porém, desvantagem no estabelecimento (Jackson 1981).

O número de sementes e de frutos recolhidos nas peneiras coletoras não representa a totalidade de propágulos produzidos. Greene \& Johnson (1994) observaram que aproximadamente a metade da produção foi perdida para granívoros e frugívoros antes da queda; a subestimativa é ainda maior durante períodos de menor produção, quando o consumo é maior e, também, naquelas espécies que amadurecem seus frutos aos poucos, tendo desta forma, mais frutos consumidos na própria planta (Chapman et al. 1994). Além disto, espécies com sementes de tamanho muito pequeno podem não ter sido incluídas na análise devido a problemas metodológicos, que incluem a malha da peneira coletora e a acuidade visual na triagem.

A produção de propágulos seguiu um padrão bastante sazonal, que não foi acompanhado pelo número de espécies dispersando ao longo dos meses. Apesar do número de espécies manter-se constante ao longo do ano, diminuindo pouco durante os meses de inverno, mais secos, o número de propágulos produzidos variou muito.

Como foi observado por Heideman (1989), a percentagem de espécies em flor ou fruto não é um bom indicador da abundância de flores e frutos. Estas diferenças demonstram que nem sempre o número de espécies reflete a disponibilidade de frutos, que poderiam ser utilizados como alimento para frugívoros (White 1994).

O que é amostrado nas peneiras provém, em geral, das plantas que estão frutificando ao redor delas. Mais de 50\% das espécies que tiveram propágulos coletados neste estudo, foram amostradas no trabalho fitossociológico realizado no mesmo local por Gomes (1992), refletindo um predomínio de dispersão local. Walker \& Neris (1993) demonstraram que 25 a $50 \%$ das sementes coletadas provinham de espécies frutificando num raio de apenas 2 $\mathrm{m}$ das peneiras. $\mathrm{O}$ mesmo não foi verificado por Chapman et al. (1994), que coletaram apenas $19 \%$ das espécies naquelas condições.

Formas de crescimento, síndromes de dispersão e estádios sucessionais - Entre as espécies, a forma de crescimento predominante foi a arbórea, com 26 espécies liberando propágulos no período de estudo. Roizman (1993), estudando a chuva de sementes num fragmento de mata secundária de 10 ha, também em São Paulo, encontrou apenas 18 espécies arbóreas. As densidades amostradas para cada espécie são semelhantes às obtidas por aquela autora, não ultrapassando, para a maioria, 10 propágulos $/ \mathrm{m}^{2} / \mathrm{mês}$. O padrão sazonal também foi semelhante. A forma de crescimento que produziu relativamente o menor número de propágulos foi a arbórea. Segundo Ramirez (1993), as espécies arbóreas possuem a menor capacidade de produzir sementes, assim como as maiores médias de flores e de frutos abortados.

A maior quantidade de propágulos foi liberada pelas 12 espécies de lianas, que responderam por quase 
$50 \%$ do total, demonstrando alto poder regenerativo, o que pode estar sendo prejudicial para a comunidade. Segundo Putz (1980), onde lianas são abundantes, devido a competição, a regeneração da vegetação arbórea pode ser retardada por muitos anos.

Entre as síndromes de dispersão, a percentagem de anemocoria na comunidade $(33 \%)$ foi alta para florestas tropicais e, provavelmente, indica o grau de perturbação da mata estudada, onde a ausência de dossel contínuo facilita a dispersão das espécies com esta síndrome. A dispersão anemocórica é característica de espécies de estádios iniciais da sucessão, de árvores do estrato superior, de epífitas (Pijl 1982, Howe \& Smallwood 1982) e, também, de muitas lianas que dominam o sub-bosque e estão presentes no dossel da mata do parque. As espécies anemocóricas dispersaram propágulos de forma mais sazonal, com picos em outubro e novembro, ou seja, no início da estação chuvosa. As pequenas e leves sementes anemocóricas são facilmente derrubadas com a chuva, o que explica o pico de dispersão concomitante ao início das chuvas. Jackson (1981) observou padrão semelhante em Nova Lombardia, com aumento no número de espécies anemocóricas do final da estação seca até o meio da estação chuvosa.

A anemocoria é a segunda síndrome de dispersão em importância para todas as espécies da comunidade, antecedida somente pela zoocoria que, em florestas tropicais conservadas é a síndrome de mais de $75 \%$ das espécies (Howe \& Smallwood 1982, Ibarra-Manríquez et al. 1991). Martins et al. (1995) avaliaram as síndromes de dispersão de 520 espécies arbóreas de Mata Atlântica e encontraram 75\% de zoocoria e $18 \%$ de anemocoria.

Na reserva do Parque do Estado foram observados dois picos de queda de folhas e troncos, um em maio/junho e outro em outubro/novembro (Teixeira et al. 1992). O pico de liberação de propágulos das espécies anemocóricas coincide, desta forma, com a época de maior queda de folhas, favorecendo a dispersão dos diásporos.

As espécies zoocóricas dispersaram propágulos principalmente entre dezembro e fevereiro, ou seja, no meio da estação chuvosa. Nesta estação, o aumento da umidade e da insolação deve favorecer o amadurecimento de frutos suculentos (Gautier-Hion 1990), tomando-os mais atrativos aos dispersores. A liberação de propágulos zoocóricos, nesta época, está relacionada à maturação dos frutos carnosos em época de melhores condições de germinação e crescimento de plântulas (Morellato et al. 1989).

O número de propágulos variou ao longo do ano, mas o número de espécies liberando frutos carnosos, excetuando-se maio, manteve-se praticamente constante. Em florestas tropicais sazonais, as espécies com frutos zoocóricos mostram um pico de amadurecimento durante a estação chuvosa (Rathcke \& Lacey 1985), embora existam frutos carnosos sendo produzidos durante todo o ano, que servem como importante fonte alimentar para animais durante períodos de escassez (White 1994).

Os frutos autocóricos, apesar de não terem mostrado aqui nenhum padrão nítido, por serem na maioria dos casos explosivos, são adaptados à deiscência durante os meses mais secos, quando a umidade relativa é baixa (Murali \& Sukumar 1994).

Na comunidade, as espécies secundárias foram responsáveis pela produção da maior parte dos propágulos liberados na chuva de sementes, o que pode ser explicado pelo fato das plantas de estádios iniciais da sucessão possuírem períodos mais longos de frutificação, além de frutificarem anualmente (Rathcke \& Lacey 1985, Putz \& Appanah 1987). Segundo Alvarez-Buylla \& Garcia-Barrios (1991), algumas espécies pioneiras e secundárias podem depender mais da chuva de sementes do que do banco de sementes no solo para sua regeneração, já que o banco pode não ser igualmente duradouro para todas. A grande produção observada por espécies secundárias, portanto, poderia estar abastecendo o estoque de sementes no solo.

A chuva de sementes nem sempre reflete a vegetação de um local, principalmente quando estudada por um período tão curto, já que padrões supraanuais só podem ser detectados com estudos de longo prazo (Schupp 1990, Walker \& Neris 1993). Muitas das espécies arbóreas citadas por Gomes (1992) como dominantes no local, não apresentaram nenhum propágulo amostrado no período. Alguns trabalhos demonstraram ser comum entre as espécies a ocorrência de anos de alta produção de sementes, entremeados com anos de baixa ou nenhuma produção (Leite \& Rankin 1981, Schupp 1990, Nicholas et al. 1992, Alvarez-Sanchéz \& Guevara-Sada 1993). Há algumas espécies que apesar de produzirem anualmente, o fazem em 
pequena quantidade e, além disto, pelas alterações na estrutura da floresta, muitas populações do dossel podem apresentar indivíduos em fases préreprodutivas. Estas podem ser explicações para a ausência de propágulos amostrados de algumas espécies, mas só estudos mais detalhados da estrutura e da fenologia destas populações podem determinar o seu potencial de regeneração.

Agradecimentos - à FAPESP, pela bolsa concedida, e ao Eduardo Pereira Cabral Gomes, pela colaboração na etapa de campo.

\section{Referências bibliográficas}

AIZEN, M.A. \& FEINSINGER, P. 1994. Forest fragmentation, pollination, and plant reprodution in a Chaco dry forest, Argentina. Ecology 75:330-351.

ALVAREZ-BUYLLA, E.R. \& GARCIA-BARRIOS, R. 1991. Seed and forest dynamics: a theoretical framework and an example from the Neotropics. Am. Nat. 137:133-154.

ALVAREZ-SANCHEZ, J. \& GUEVARA-SADA, S. 1993. Litterfall dynamics in a Mexican lowland tropical rain forest. Trop. Ecol. 34:127-142.

AUGSPURGER, C.K. \& FRANSON, S.E. 1988. Input of wind-dispersed seeds into light-gaps and forest sites in a neotropical forest. J. Trop. Ecol. 4:239-252.

BAIDER, C. 1994. O banco de sementes e de plântulas na sucessão da Mata Atlântica. São Paulo. Dissertação de mestrado, Universidade de São Paulo, São Paulo.

BAITELLO, J.B., AGUIAR, O.T. \& PASTORE, J.A. 1983/85. Essências florestais da Reserva Estadual da Cantareira (São Paulo - Brasil). Silvicul. São Paulo 17/19:61-84.

BARBOSA, O., BAITELLO, J.B., MAINIERI, C., MONTAGNA, R.G. \& NEGREIROS, O.C. 1977/78. Identificação e fenologia de espécies arbóreas da Serra da Cantareira (São Paulo). Silvicul. São Paulo 11/12:1-86.

BUDOWSKY, G. 1965. Distribution of tropical American rain forest species in the light of sucessional processes. Turrialba 15:40-42.

BULLOCK, S.H. \& SOLIS-MAGALLANES, J.A. 1990. Phenology of canopy trees of a tropical deciduous forest in México. Biotropica 22:22-35.

CHAPMAN, C.A., WRANGHAM, R. \& CHAPMAN, L.J. 1994. Indices of habitat-wide fruit abundance in tropical forests. Biotropica 26: 160-171.

FOSTER, S.A. \& JANSON, C.H. 1985. The relationship between seed size and establishment conditions in tropical woody plants. Ecology 66:773-780.

FOURNIER, L.A. 1976. Observaciones fenológicas en el bosque húmedo de pre-montano de San Pedro de Montes de Oca, Costa Rica. Turrialba 26:54-59.

GARWOOD, N.C. 1983. Seed germination in a seasonal tropical forest in Panama: a community study. Ecol. Monogr. 53:159-181.

GAUTIER-HION, A. 1990. Interactions among fruit and vertebrate fruit-eaters in an African tropical rain forest. In Reproductive ecology of tropical forest plants (K.S. Bawa \& M. Hadley, eds.). The Partenon Group, Paris, p.219-230.

GOMES, E.P.C. 1992. Fitossociologia do componente arbóreo de um trecho de mata em São Paulo, SP. Dissertação de mestrado, Universidade de São Paulo, São Paulo.
GREENE, D.F. \& JOHNSON, E.A. 1994. Estimating the mean annual seed production of trees. Ecology 75:642-647.

GRIME, J.P., MASON, G., CURTIS, A.V., RODMAN, S.R., BAND, M.A., MOWFORTH, A.M., SHAW, N. \& SHAW, S. 1981. A comparative study of germination characteristics in a local flora. J. Ecol. 69:1017-1059.

HEIDEMAN, P.D. 1989. Temporal and spatial variation in the phenology of flowering and fruiting in a tropical rainforest. J. Ecol. 77:1059-1079.

HERRERA, C.M., JORDANO, P., LÓPEZ-SORIA, L. \& AMAT, J.A. 1994. Recruitment of a mast-fruiting, birddispersed tree: bridging frugivore activity and seedling establishment. Ecol. Monogr. 64:315-344.

HOEHNE, F.C., KUHLMANN, M. \& HANDRO, O. 1941. O Jardim Botânico de São Paulo. Secretaria da Agricultura, Indústria e Comércio de São Paulo, São Paulo.

HOWE, H.F. \& SMALLWOOD, J. 1982. Ecology of seed dispersal. Annu. Rev. Ecol. Syst. 13:201-228.

IBARRA-MANRÍQUEZ, G., SÁNCHEZ-GARFIAS, B. \& GONZÁLEZ-GARCIA, L. 1991. Fenologia de lianas y arboles anemocoros en una Selva Calido-Humeda de México. Biotropica 23:242-254.

JACKSON, J.F. 1978. Seasonality of flowering and leaf fall in a Brazilian subtropical lower montane moist forest. Biotropica 10:38-42.

JACKSON, J.F. 1981. Seed size as a correlate of temporal and spatial patterns of seed fall in a neotropical forest. Biotropica 13:121-130.

JOLY, A.B. 1985. Botânica. Nacional, São Paulo.

KOEPPEN, W. 1948. Climatologia. Fundo de Cultura Economica, México.

LEITE, A.M.C. \& RANKIN, J.M. 1981. Ecologia de sementes de Pithecolobium racemosum Ducke. Acta Amazônica 11:309-318.

LUGO, A.E. \& FRANGI, J.L. 1993. Fruit fall in the Luquillo Experimental Forest, Puerto Rico. Biotropica 25:73-84.

MARTINS, S. E., POMPÉIA, S. L. \& ROSSI, L. 1995. Síndromes de dispersão de espécies arbóreas da Mata Atlântica de encosta no estado de São Paulo. In Resumos do 46ํㅡㄹ Congresso nacional de botânica (Sociedade botânica do Brasil, ed.), SBB, Ribeirão Preto, p.167.

MATTHES, L.A.F., LEITAO FILHO, H.F. \& MARTINS, F.R. 1988. Bosque dos Jequitibás (Campinas, SP): Composição florística e estrutura fitossociológica do estrato arbóreo. In Anais do V Congresso da Sociedade botânica de São Paulo. Campinas, p.55-76.

MELHEM, T.S., GIULIETTI, A.M., FORERO, E., BARROSO, G.M., SILVESTRE, M.S.F., JUNG, S.L.. MAKINO. H.; MELO, M.M.R.F., CHIEA, S.C., WANDERLEY, M.G.L., KIRIZAWA, M. \& MUNIZ, C. 1981. Planejamento para a elaboração da "Flora Fanerogâmica da Reserva do Parque Estadual das Fontes do Ipiranga (São Paulo, Brasil)". Hoehnea 9:63-74.

MORELLATO, L.P.C. 1992. Sazonalidade e dinâmica de ecossistemas florestais na Serra do Japi. In História natural da Serra do Japi (L.P.C. Morellato, ed.). UNICAMP/ FAPESP, Campinas, p.98-109.

MORELLATO, L.P.C., RODRIGUES, R.R., LEITÃO FILHO, H.F. \& JOLY, C.A. 1989. Estudo comparativo da fenologia de espécies arbóreas de floresta de altitude e floresta mesófila semidecídua na Serra do Japi, Jundiaí, São Paulo. Revta. brasil. Bot. 12:85-98.

MUELLER-DOMBOIS, D. \& ELLENBERG. H. 1974. Aims and methods of vegetation ecology. John Wiley. New York. 
MURALI, K.S. \& SUKUMAR, R. 1994. Reproductive phenology of a tropical dry forest in Mudumalai, Southern India. J. Ecol. 82:759-767.

NASTRI, V.D.F., CATHARINO, E.L.M., ROSSI, L.; BARBOSA, L.M., PIRRÉ, E., BEDINELLI, C., ASPERTI, L.M., PORTA, R.O. \& COSTA, M.P. 1992. Estudos fitossociológicos em uma área do Instituto de Botânica de São Paulo utilizados em programas de Educação Ambiental. In Anais do 2ํ Congresso nacional sobre essências nativas (Instituto Florestal, ed.), São Paulo, p. 219-225.

NEWSTROM, L.E., FRANKIE, G.W. \& BAKER, H.G. 1994. A new classification for plant phenology based on flowering patterns in lowland tropical rain forest trees at La Selva, Costa Rica. Biotropica 26:141-159.

NICHOLAS, N.S., ZEDAKER, S.M., EAGAR, C. \& BONNER, F.T. 1992. Seedling recruitment and stand regeneration in spruce-fir forests of the Great Smoky Montains. Bull. Torrey Bot. Club 119:289-299.

OPLER, P.A., FRANKIE, G.W. \& BAKER, H.G. 1976. Rainfall as a factor in the release, timing, and synchronization of anthesis by tropical trees and schrubs. J. Biogeogr. 3:231236.

PIJL, L. van der 1982. Principles of dispersal in higher plants. Springer-Verlag, Berlin.

PRIMACK, R.B. 1985. Longevity of individual flowers. Annu. Rev. Ecol. Syst. 16:15-37.

PRIMACK, R.B. 1987. Relationships among flowers, fruits. and seeds. Annu. Rev. Ecol. Syst. 18:409-430.

PUTZ, F.E. 1980. Lianas vs. trees. Biotropica 12:224-225.

PUTZ, F.E. 1984. The natural history of lianas on Barro Colorado Island, Panama. Ecology 65:1713-1724.

PUTZ, F.E. \& APPANAH, S. 1987. Buried seeds, newly dispersed seeds and the dynamics of a Lowland Forest in Malaysia. Biotropica 19:326-333.

RAMIREZ, N. 1993. Produccion y costo de frutos y semillas entre formas de vida. Biotropica 25:46-60.

RATHCKE, B. \& LACEY, E.P. 1985. Phenological patterns of terrestrial plants. Annu. Rev. Ecol. Syst. 16:179-214.
RICHARDS, P.W. 1952. The tropical rain forest. University Press, Cambridge, p.40-53.

ROBERTS, H.A. 1986. Seed persistence in soil and seasonal emergence in plant species from different habitats. J. Appl. Ecol. 23:639-656.

ROIZMAN, L. 1993. Fitossociologia e dinâmica do banco de sementes de populações arbóreas de floresta secundária em São Paulo, SP. São Paulo. Dissertação de mestrado, Universidade de São Paulo, São Paulo.

ROSSI, L. 1994. A flora arbóreo-arbustiva da mata da Reserva da Cidade Universitária "Armando de Salles Oliveira" (São Paulo, Brasil). Bol. Inst. Bot. 9:1-105.

SCHUPP, E.W. 1990. Annual variation in seedfall, postdispersal predation, and recruitment of a neotropical tree. Ecology 71:504-515.

SILVERTOWN, J.W. 1981. Seed size, life span, and germination date as coadapted features of plant life history. Am. Nat. 118:860-864.

STRUFFALDI-DE-VUONO, Y. 1985. Fitossociologia do estrato arbóreo da floresta da Reserva Biológica do Instituto de Botânica (São Paulo, SP). São Paulo. Tese de doutorado, Universidade de São Paulo, São Paulo.

TABARELLI, M., VILLANI, J.P. \& MANTOVANI, W. 1993. Aspectos da sucessão secundária em trecho de floresta atlântica no Parque Estadual da Serra do Mar. Rev. Inst. Florestal 5:99-112.

TEIXEIRA, C.B., DOMINGOS, M., REBELO. C.F. \& MORAES, R.M. 1992. Produção de serapilheira em floresta residual da cidade de São Paulo: Parque Estadual das Fontes do Ipiranga. In Anais do 2을 Congresso nacional sobre essências nativas (Instituto Florestal, ed.), São Paulo, p.785-789.

WALKER, L.A. \& NERIS, L.E. 1993. Posthurricane seed rain dynamics in Puerto Rico. Biotropica 25:408-418.

WHITE, L.J.T. 1994. Pattern of fruit-fall phenology in the Lopé Reserve, Gabon. J. Trop. Ecol. 10:289-312.

WRIGHT, S.J. \& SCH AIK, C.P.van 1994. Light and the phenology of tropical trees. Am. Nat. 143:192-199. 